\title{
TRABALHO, BEM-ESTAR E QUALIDADE DE VIDA: ESTUDO DE CASO EM UMA AUTARQUIA GAÚCHA
}

\author{
Gleberson de Santana dos Santos \\ Luane Lopes Alves ${ }^{*}$ \\ Fabio Rigo ${ }^{* *+}$ \\ Andreia Aparecida Pandolfi dos Santos ${ }^{* * *}$
}

\begin{abstract}
RESUM0: 0 fator humano, nos últimos tempos, tem sido encarado como fator chave para aumentar o desempenho, produtividade das organizações, razão pela qual corporações têm investido em programas voltados à promoção de bem-estar dos seus colaboradores com a finalidade de conquistar maior grau de comprometimento e envolvimento. Neste sentido, este trabalho propôs-se a investigar a percepção de bem-estar dos servidores públicos de uma autarquia do município de Pelotas/RS, pertencentes à Divisão de Veículos e Oficina (DV0). Metodologicamente, este estudo se classifica como descritivo de abordagem quantitativa. Como instrumento de coleta de dados utilizaram-se os questionários que foram aplicados aos servidores que ocupam os cargos de motoristas, mecânicos, operadores de máquinas, lavador e operário. A coleta de dados ocorreu durante os meses de junho e julho de 2017. Conclui-se que dentro do construto de bem-estar no trabalho, 0 aspecto envolvimento obteve menor média (x 2,68, DP 0,93). Quanto ao aspecto "compromisso e satisfação" apresentou a melhor média a percepção dos colaboradores na relação com 0 chefe imediato $(x 4,4, \mathrm{DP} 1,18)$.
\end{abstract}

PALAVRAS-CHAVE: Trabalho; Bem-estar; Compromisso e satisfação; Envolvimento.

\section{LABOR, WELL-BRING AND LIFE QUALITY: A CASE STUDY IN AN AUTARCHY IN SOUTH BRAZIL}

ABSTRACT: Recently the human factor is considered a key factor to increase performance and productivity. This is the reason why firms have invested in programs for the enhancement of well-being of their collaborators so that they would achieve a higher degree of commitment and involvement. The perception of well-being by public servants belonging to the Vehicle and Workshop Sector (VWS) of an autarchy in Pelotas, Brazil, is analyzed. Current descriptive and quantitative study comprises data collected through questionnaires applied to servants such as drivers, mechanics, machine operators, car washers and workers. Data were collected between June and July 2017. Results show that within well-being in the working place, involvement had the least average ( $\mathrm{x}$ 2.68; DP 0.93), whereas "commitment and satisfaction" had the best average on collaborators' perception for their immediate boss (x 4.4; DP 1.18).

KEYWORDS: Labor; Well-being; Commitment and satisfaction; Involvement.

\section{INTRODUÇÃO}

Estabelecer que a produtividade e a gestão da qualidade de vida no trabalho estão intimamente ligadas. Para Silva e Matos (2003), essas duas entidades podem representar para a instituição e para o colaborador motivos para 0 desenvolvimento ou para a estagnação, dependendo do atendimento ou não de condições humanas de trabalho e convivência. Considerando essas afirmações, podemos citar a

\footnotetext{
Mestre em Administração, pela Universidade do Oeste de Santa Catarina (UNOESC). Docente substituto na Universidade Federal de Pelotas (UFPel) e nos cursos de Pós-graduação da Faculdade de Tecnologia Senac RS, Brasil. E-mail: glebersonsantana@hotmail.com

** Tecnóloga em Processos Gerenciais, pela Universidade Federal de Pelotas (UFPel), Brasil.

*** Tecnólogo em Processos Gerenciais, pela Universidade Federal de Pelotas (UFPel), Brasil

${ }^{* * *}$ Mestre em Administração, pela Universidade do Sul de Santa Catarina (UNISUL), Brasil.
} 
qualidade de vida no trabalho (QVT) como um fator de desenvolvimento humano, crescimento pessoal. Entretanto, do ponto de vista organizacional, a QVT pode ser observada como ferramenta para a obtenção de altos níveis de produção. De posse do conhecimento de tais fenômenos, a gestão de pessoas deve assumir papel intermediário entre 0 objetivo da empresa e 0 ambiente motivacional proporcionado por boas condições de trabalho.

Dessa forma, pode-se admitir que colaboradores motivados, bem capacitados e remunerados tendem a apresentar uma produtividade acima da média. Do ponto de vista gerencial, observase que fatores como supervisão, condições de trabalho, remuneração, benefícios extras e plano de carreira afetam a QVT, sendo, segundo Gouveia et al. (2012), a natureza do cargo o que afeta mais diretamente 0 trabalhador, cabendo então uma análise diferenciada para cada tipo de trabalhador.

A qualidade de vida no trabalho pode assumir diferentes características, variantes entre cargos, além de ter variações sutis entre indivíduos. Uma das profissões que sofre constantemente a influência de sua situação, bem como de inúmeros outros fatores externos é a profissão de motorista, seja ele de carga ou passageiros, leve ou pesada. Um conceito definidor da profissão de motorista, pelo Ministério do Trabalho e Emprego, corroborado na literatura (Penteado et al., 2008), é de que este é 0 trabalhador que desempenha o conjunto de atividades de transporte, coleta, guincho, remoção e entrega de cargas em geral, dentre outras funções.

Sabe-se, porém, que embora bem definidas as atribuições da referida profissão, 0 desenvolvimento de um trabalho completo envolve outras atividades adjacentes como esforço físico, comunicação, entrega de documentos, entre outras. Esse conjunto de ações torna a profissão de motorista uma das mais desgastantes se considerarmos o local de trabalho como sendo uma "cabine", altamente restritiva, as atividades de higiene e cuidados com alimentação e sono na maioria das vezes arbitrárias e negligenciadas (BATTISTON; CRUZ; HOFFMANN, 2006).
Portanto, cabe à comunidade científica da gestão das pessoas e do desempenho organizacional mensurar a importância do impacto das citadas influências na qualidade de vida durante a carreira de motorista bem como a influência na sua produtividade. Considerando as diferenças nos planos de carreira entre as áreas privada e pública, é importante também a verificação dessas relações em diferentes zonas de atuação dos motoristas, sejam eles funcionários públicos de carga pesada, leve ou atividades alternativas.

Segundo Rueda, Serenini e Meireles (2014), a confiança no trabalho é um fator determinante para a garantia do bom funcionamento das relações de trabalho, influenciando na produtividade. Entretanto, na rede pública, embora estável, o funcionário/colaborador nem sempre protagoniza seu melhor desempenho e entrega ao cliente 0 melhor de sua produtividade. Assim, é de justa relevância a busca pela produtividade e aumento na competitividade perante a instituição por meio da melhora da qualidade de vida desses profissionais.

Tangenciando sobre a temática bem-estar laboral, sabe-se que na perspectiva psicológica, 0 bem-estar no trabalho representa 0 estado mental positivo formado pela articulação de três vínculos denominados satisfação no trabalho, envolvimento com 0 trabalho e comprometimento organizacional afetivo. No que tange à satisfação, esta se refere às relações do colaborador com as pessoas no local do trabalho (chefia e colegas); retribuições organizacionais ofertadas pela organização (salários, benefícios e promoções) e atividade que realiza (tarefa). (SIQUEIRA; ORENGO; PEIRÓ, 2014).

Segundo os autores, o envolvimento exprime a (a) existência de uma meta a ser alcançada por meio de atividades; (b) os desafios impostos pelas atividades a serem vencidos pela atividade do indivíduo e (c) existência de feedback oferecido pelas próprias atividades realizadas. Já a perspectiva do comprometimento organizacional afetivo trata da identificação do indivíduo com a organização e um forte desejo de ela permanecer trabalhando. (SIQUEIRA; ORENGO; PEIRÓ, 2014). 
0 tema bem-estar no trabalho está contido no conjunto de aspectos que abrangem a qualidade de vida no trabalho (QVT). Sobre QVT, França (2014, p. 167) conceitua como a "capacidade de administrar o conjunto de ações, incluindo diagnóstico, implantação de melhorias e inovações gerenciais, tecnológicas e estruturais no ambiente de trabalho alinhada e construída na cultura organizacional, com prioridade absoluta para o bem-estar das pessoas da organização".

Em pesquisa sobre QVT no Brasil nos últimos 30 anos (1988-2017), observa-se que tem aumentado 0 número de publicações de artigos científicos em periódicos com Qualis/Capes, nos três últimos quinquênios, cuja média de publicações é de em torno de quatro por ano, conforme demonstrado no Quadro 1. A pesquisa foi realizada na base de dados Scientific Periodicals Electronic Library, onde se filtrou a palavrachave "qualidade de vida no trabalho" e limitou-se ao período de 1988-2017. Foram pesquisados 68 artigos científicos, sendo que em 2017 (julho) não foram encontradas pesquisas.

Quadro 1. Número de publicações sobre QVT por quinquênio (1988-2017)

\begin{tabular}{|c|c|c|}
\hline Período & $\begin{array}{l}\text { Número de } \\
\text { publicações }\end{array}$ & $\begin{array}{l}\text { Frequência } \\
\text { relativa }\end{array}$ \\
\hline $2013-2017$ & 26 & $38,2 \%$ \\
\hline $2008-2012$ & 19 & $27,9 \%$ \\
\hline $2003-2007$ & 15 & $22,1 \%$ \\
\hline $1998-2002$ & 5 & $7,4 \%$ \\
\hline $1993-1997$ & 1 & $1,5 \%$ \\
\hline $1988-1992$ & 2 & $2,9 \%$ \\
\hline Total & $\mathbf{6 8}$ & $\mathbf{1 0 0 , 0 \%}$ \\
\hline
\end{tabular}

Fonte: dados da pesquisa (2018).

No que se refere aos periódicos que mais publicaram sobre o tema durante 0 período, notase maior concentraram em revistas com Qualis extrato A2, segundo classificação da Comissão de Aperfeiçoamento de Pessoal de Nível Superior - Capes, destacando-se os periódicos Revista de Administração (8,8\%), Revista de Administração Contemporânea $(5,9 \%)$ e Organizações \& Sociedade $(4,4 \%)$. Dos periódicos classificados em B1 destacou-se a REAd. Revista Eletrônica de Administração (5,9\%), como demonstra 0 Quadro 2.

Quadro 2. Periódicos que mais publicaram sobre o tema QVT (1988-2017)

(Continua)

\begin{tabular}{|l|c|c|c|c|}
\hline \multicolumn{1}{|c|}{ Periódico } & $\begin{array}{c}\text { No } \\
\text { Publ. }\end{array}$ & FR (\%) & Qualis & FI \\
\hline Revista de Administração & 6 & $8,8 \%$ & A2 & 0,624 \\
\hline $\begin{array}{l}\text { REAd. Revista Eletrônica de } \\
\text { Administração }\end{array}$ & 4 & $5,9 \%$ & B1 & 0,425 \\
\hline $\begin{array}{l}\text { Revista de Administração } \\
\text { Contemporânea }\end{array}$ & 4 & $5,9 \%$ & A2 & 1,119 \\
\hline Organizações \& Sociedade & 3 & $4,4 \%$ & A2 & 0,543 \\
\hline Cadernos EBAPE.BR & 2 & $2,9 \%$ & A2 & 0,729 \\
\hline $\begin{array}{l}\text { GESTÃo.Org - Rev. Eletr. } \\
\text { de Gestão Organizacional }\end{array}$ & 2 & $2,9 \%$ & B3 & 0,195 \\
\hline $\begin{array}{l}\text { Interface - Rev. do C. de } \\
\text { Ciências Sociais Aplicadas }\end{array}$ & 2 & $2,9 \%$ & B3 & 0,025 \\
\hline Reuna & 2 & $2,9 \%$ & B2 & 0,133 \\
\hline $\begin{array}{l}\text { Revista Administração em } \\
\text { Diálogo }\end{array}$ & 2 & $2,9 \%$ & B3 & 0,000 \\
\hline $\begin{array}{l}\text { Revista Capital Científico - } \\
\text { Eletrônica }\end{array}$ & 2 & $2,9 \%$ & B3 & 0,080 \\
\hline $\begin{array}{l}\text { Revista de Administração } \\
\text { da UFSM }\end{array}$ & 2 & $2,9 \%$ & B2 & 0,678 \\
\hline $\begin{array}{l}\text { Revista de Administração } \\
\text { da Unimep }\end{array}$ & 2 & $2,9 \%$ & B2 & 0,187 \\
\hline $\begin{array}{l}\text { Revista de Administração e } \\
\text { Inovação }\end{array}$ & 2 & $2,9 \%$ & B1 & 0,489 \\
\hline $\begin{array}{l}\text { Revista de Ciências da } \\
\text { Administração }\end{array}$ & 2 & $2,9 \%$ & B1 & 0,478 \\
\hline Revista de Negócios & 2 & $2,9 \%$ & B2 & 0,299 \\
\hline Revista Economia \& Gestão & 2 & $2,9 \%$ & B2 & 0,225 \\
\hline $\begin{array}{l}\text { Revista Eletrônica de } \\
\text { Ciência Administrativa }\end{array}$ & 2 & $2,9 \%$ & B1 & 0,262 \\
\hline $\begin{array}{l}\text { Revista Gestão } \\
\text { Organizacional }\end{array}$ & 2 & $2,9 \%$ & B4 & 0,173 \\
\hline
\end{tabular}


(Conclusão)

(Conclusão)

\begin{tabular}{|l|c|c|c|c|}
\hline \multicolumn{1}{|c|}{ Periódico } & $\begin{array}{c}\text { No }^{\text {Publ. }} \\
\text { Pul }\end{array}$ & FR (\%) & Qualis & FI \\
\hline $\begin{array}{l}\text { Revista Gestão \& } \\
\text { Planejamento }\end{array}$ & 2 & $2,9 \%$ & B2 & 0,217 \\
\hline $\begin{array}{l}\text { Revista Organizações em } \\
\text { Contexto }\end{array}$ & 2 & $2,9 \%$ & B1 & 0,167 \\
\hline $\begin{array}{l}\text { Outros periódicos (com } \\
\text { apenas 1 publicação) }\end{array}$ & 19 & $27,9 \%$ & - & - \\
\hline Total & $\mathbf{6 8}$ & $\mathbf{1 0 0 , 0 \%}$ & & \\
\hline
\end{tabular}

Fonte: dados da pesquisa (2018).

Legenda:

№ Publ. - Número de publicações

FR (\%) - Frequência relativa

FI - Fator de impacto 5 anos, referência 2015 (2010-2014)

Em relação aos autores que mais publicaram sobre a temática neste período, encontram-se os pesquisadores: Ana Cristina Limongi-França (Universidade de São Paulo), Silvio Roberto Stefano (Universidade Estadual do Centro-Oeste), Antônio Luiz Marques e Lúcio Flávio Renault de Moraes, ambos filiados à Universidade Federal de Minas Gerais, conforme apresenta o Quadro 3.

\begin{tabular}{|l|c|c|c|}
\hline \multicolumn{1}{|c|}{ Autores } & $\begin{array}{c}\mathbf{N}^{0} \\
\text { Publ. }\end{array}$ & FR (\%) & $\begin{array}{c}\text { Filiação / } \\
\text { Sigla }\end{array}$ \\
\hline Jássio Pereira de Medeiros & 2 & $2,9 \%$ & UFRN \\
\hline Kely César Martins de Paiva & 2 & $2,9 \%$ & UFMG \\
\hline Lucas Charão Brito & 2 & $2,9 \%$ & UFSM \\
\hline Luis Felipe Dias Lopes & 2 & $2,9 \%$ & UFSM \\
\hline Luis Paulo Bresciani & 2 & $2,9 \%$ & USCS \\
\hline Maria Auxiliadora Diniz de Sá & 2 & $2,9 \%$ & UFPB \\
\hline Nilo Sergio Guidelli & 2 & $2,9 \%$ & USCS \\
\hline Suzana da Rosa Tolfo & 2 & $2,9 \%$ & UFSC \\
\hline Valeska Nahas Guimarães & 2 & $2,9 \%$ & UFSC \\
\hline Outros (com apenas 1 publicação) & 21 & $30,9 \%$ & - \\
\hline Total & $\mathbf{6 8}$ & $\mathbf{1 0 0 , 0 \%}$ & \\
\hline
\end{tabular}

Fonte: dados da pesquisa (2018).

0 Quadro 4 apresenta a evolução das pesquisas sobre QVT durante o período de 1988 a 2017.

Quadro 4. Evolução das pesquisas sobre QVT (1988-2017)

Quadro 3. Autores que mais publicaram sobre o tema QVT (1988-2017)

(Continua)

\begin{tabular}{|l|c|c|c|}
\hline \multicolumn{1}{|c|}{ Autores } & $\begin{array}{c}\text { No } \\
\text { Publ. }\end{array}$ & FR (\%) & $\begin{array}{c}\text { Filiação / } \\
\text { Sigla }\end{array}$ \\
\hline Ana Cristina Limongi-França & 5 & $7,4 \%$ & USP \\
\hline Silvio Roberto Stefano & 4 & $5,9 \%$ & Unicentro \\
\hline Antônio Luiz Marques & 3 & $4,4 \%$ & UFMG \\
\hline Lúcio Flávio Renault de Moraes & 3 & $4,4 \%$ & UFMG \\
\hline Andréa Yumi Sugishita Kanikadan & 2 & $2,9 \%$ & FECAP \\
\hline Andressa Hennig Silva & 2 & $2,9 \%$ & UFSM \\
\hline Cláudia Aparecida Avelar Ferreira & 2 & $2,9 \%$ & PUC-MG \\
\hline Cristina Amélia Carvalho & 2 & $2,9 \%$ & UFRGS \\
\hline $\begin{array}{l}\text { Débora Coutinho Paschoal } \\
\text { Dourado }\end{array}$ & 2 & $2,9 \%$ & UFPE \\
\hline Eda Conte Fernandes & 2 & $2,9 \%$ & UFRGS \\
\hline Edilene de Oliveira Pereira Garcia & 2 & $2,9 \%$ & UMSP \\
\hline
\end{tabular}

\begin{tabular}{|c|c|c|}
\hline Autor & Ano & Objetivos \\
\hline $\begin{array}{l}\text { El-Aouar, } \\
\text { Vasconcelos } \\
\text { e Veiga Neto }\end{array}$ & 2016 & $\begin{array}{l}\text { Compreender como a inserção da } \\
\text { música no ambiente de trabalho } \\
\text { contribui para alcançar a Qualidade da } \\
\text { Vida no Trabalho (QVT), na perspectiva } \\
\text { do bem-estar biopsicossocial e } \\
\text { organizacional. }\end{array}$ \\
\hline Cavedon & 2014 & $\begin{array}{l}\text { Identificar como a qualidade de vida } \\
\text { no trabalho é afetada em decorrência } \\
\text { das percepções olfativas e quais as } \\
\text { implicaçôes na saúde dos servidores } \\
\text { que integram o Departamento de } \\
\text { Criminalística vinculado ao Instituto- } \\
\text { Geral de Perícias do Rio Grande do } \\
\text { Sul. }\end{array}$ \\
\hline $\begin{array}{l}\text { Oliveira, } \\
\text { Cavazotte e } \\
\text { Paciello }\end{array}$ & 2013 & $\begin{array}{l}\text { Examinar fatores associados aos } \\
\text { conflitos entre vida pessoal e vida } \\
\text { profissional, e suas consequências, } \\
\text { em uma amostra de trabalhadores } \\
\text { com nível superior, empregados } \\
\text { em organizaçôes de diferentes } \\
\text { setores da economia, e que } \\
\text { ocupam predominantemente cargos } \\
\text { gerenciais. }\end{array}$ \\
\hline
\end{tabular}


(Continua)

(Continua)

\begin{tabular}{|c|c|c|}
\hline Autor & Ano & Objetivos \\
\hline $\begin{array}{l}\text { Paiva e } \\
\text { Avelar }\end{array}$ & 2011 & $\begin{array}{l}\text { Descrever e analisar como se } \\
\text { encontram configuradas as variáveis } \\
\text { de qualidade de vida no trabalho na } \\
\text { central de regulação médica de um } \\
\text { Serviço de Atendimento Móvel de } \\
\text { Urgência. }\end{array}$ \\
\hline $\begin{array}{l}\text { Guidelli e } \\
\text { Bresciani }\end{array}$ & 2010 & $\begin{array}{l}\text { Analisar a relação entre inovação e } \\
\text { Qualidade de Vida no Trabalho (QVT), } \\
\text { com foco principal no ser humano, } \\
\text { dado seu papel central paraa obtenção } \\
\text { de resultados organizacionais. }\end{array}$ \\
\hline $\begin{array}{l}\text { Carvalho- } \\
\text { Freitas }\end{array}$ & 2009 & $\begin{array}{l}\text { Analisar as possíveis relações entre } \\
\text { as formas como os gestores veem } \\
\text { a deficiência, a adequação das } \\
\text { condições de trabalho, e a satisfação } \\
\text { das pessoas com deficiência em } \\
\text { relação a aspectos relevantes } \\
\text { para a manutenção da qualidade } \\
\text { de vida no trabalho, em grande } \\
\text { empresa brasileira que possui mais } \\
\text { de mil funcionários portadores de } \\
\text { deficiência, contratados. }\end{array}$ \\
\hline Paiva e Couto & 2008 & $\begin{array}{l}\text { Descrever e analisar o corpo } \\
\text { gerencial de uma empresa pública } \\
\text { no que diz respeito às variáveis de } \\
\text { qualidade de vida no trabalho e de } \\
\text { estresse ocupacional, tendo em } \\
\text { vista o contexto de reestruturacão } \\
\text { produtiva e seus multivariados } \\
\text { impactos nas atividades dos gestores } \\
\text { e nos significados atribuílos a essas } \\
\text { experiências de trabalho, implicando } \\
\text { desgastes à saúde dos indivíduos. }\end{array}$ \\
\hline $\begin{array}{l}\text { Dourado e } \\
\text { Carvalho }\end{array}$ & 2007 & $\begin{array}{l}\text { Revelar os interesses organizacionais } \\
\text { subjacentes à lógica organizacional } \\
\text { da qualidade de vida no trabalho } \\
\text { (QVT), através da técnica de análise } \\
\text { crítica do discurso (ACD) ao programa } \\
\text { de QVT do Metrorec, empresa } \\
\text { responsável pelo metrô no estado de } \\
\text { Pernambuco. }\end{array}$ \\
\hline David e Faria & 2007 & $\begin{array}{l}\text { Construir uma escala para avaliar } \\
\text { a percepção de satisfação com } \\
\text { a qualidade de vida no contexto } \\
\text { do trabalho, com a finalidade de } \\
\text { contribuir para a identificação } \\
\text { de aspectos que necessitam ser } \\
\text { aprimorados no ambiente de trabalho } \\
\text { de organizações brasileiras, visando } \\
\text { subsidiar 0 estabelecimento de } \\
\text { estratégias organizacionais. }\end{array}$ \\
\hline
\end{tabular}

\begin{tabular}{|c|c|c|}
\hline Autor & Ano & Objetivos \\
\hline $\begin{array}{l}\text { Dourado e } \\
\text { Carvalho }\end{array}$ & 2006 & $\begin{array}{l}\text { Realizar uma interpretação crítica do } \\
\text { movimento de Qualidade de Vida no } \\
\text { Trabalho (QVT), desvendando suas } \\
\text { ferramentas de instrumentalização } \\
\text { do homem pelo capital e revelar sua } \\
\text { verdadeira natureza. }\end{array}$ \\
\hline $\begin{array}{l}\text { Honório e } \\
\text { Marques }\end{array}$ & 2001 & $\begin{array}{l}\text { Investigar os impactos que as } \\
\text { demandas voltadas à adaptação } \\
\text { dos empregados do setor de } \\
\text { telecomunicações ao mercado de } \\
\text { trabalho estariam causando na } \\
\text { Qualidade de Vida no Trabalho de } \\
\text { trabalhadores de uma grande empresa } \\
\text { de telefonia celular e propor ações } \\
\text { para a gerência de Recursos Humanos } \\
\text { no que se refere ao tratamento das } \\
\text { principais. insatisfações detectadas. }\end{array}$ \\
\hline $\begin{array}{l}\text { Tolfo e } \\
\text { Piccinini }\end{array}$ & 2001 & $\begin{array}{l}\text { Discutir os resultados de pesquisas } \\
\text { sobre as melhores empresas para } \\
\text { trabalhar no Brasil, divulgadas pela } \\
\text { revista Exame nos anos de 1997, } \\
1999 \text { e } 2000 \text {. }\end{array}$ \\
\hline $\begin{array}{l}\text { Monaco e } \\
\text { Guimarães }\end{array}$ & 2000 & $\begin{array}{l}\text { Avaliar as transformações dos } \\
\text { aspectos relacionados à qualidade de } \\
\text { vida no trabalho, a partir da introdução } \\
\text { do programa de qualidade total numa } \\
\text { empresa pública prestadora de } \\
\text { serviços. }\end{array}$ \\
\hline $\begin{array}{l}\text { Albuquerque } \\
\text { e Limongi- } \\
\text { França }\end{array}$ & 1998 & $\begin{array}{l}\text { Investigar um aparente paradoxo: } \\
\text { embora a maioria das organizações } \\
\text { esteja envolvida na busca da } \\
\text { produtividade e em processos de } \\
\text { mudança com vistas a melhorar } \\
\text { seu posicionamento no mercado, a } \\
\text { qualidade de vida no trabalho vem } \\
\text { ganhando espaço nas discussões } \\
\text { acadêmicas e empresariais. }\end{array}$ \\
\hline $\begin{array}{l}\text { Fernandes e } \\
\text { Rendón }\end{array}$ & 1992 & $\begin{array}{l}\text { Apresentar técnicas adequadas, } \\
\text { tanto de coleta como de tratamento } \\
\text { de dados, minimizando certa } \\
\text { subjetividade na interpretação e na } \\
\text { analise dos resultados de investigação } \\
\text { das opiniões em relação aos fatores } \\
\text { que suportam o bem-estar dos } \\
\text { trabalhadores em determinada } \\
\text { empresa. }\end{array}$ \\
\hline
\end{tabular}


(Conclusão)

\begin{tabular}{|c|c|c|}
\hline Autor & Ano & Objetivos \\
\hline $\begin{array}{c}\text { Fernandes e } \\
\text { Gutierrez }\end{array}$ & 1988 & $\begin{array}{l}\text { Relatar e analisar os resultados } \\
\text { de um processo de concepção e } \\
\text { implantação de um projeto de QVT } \\
\text { em empresa gaúcha, em que oS } \\
\text { autores atuaram, respectivamente, } \\
\text { como consultor externo e diretor de } \\
\text { recursos humanos; propor modelo de } \\
\text { intervenção para a ação estratégica } \\
\text { da gerência de RH nos programas de } \\
\text { QVT, como contribuição às empresas } \\
\text { para melhor utilização dos seus } \\
\text { recursos humanos. }\end{array}$ \\
\hline
\end{tabular}

Fonte: dados da pesquisa (2018).

Diante da análise do Quadro 4 nota-se que os estudos sobre QVT têm convergido para detectar a influência de fatores ambientais na satisfação e QVT de colaboradores de áreas distintas do segmento de mercado. Outros trabalhos encontram-se centrados no estudo do estresse e pressões exercidas no ambiente de trabalho e sua influência na percepção de QVT sob 0 aspecto psicossocial. Já outras pesquisas têm concentrado na proposição de modelos e construtos para mensuração de QVT sob diversas dimensões (remuneração, condições de trabalho, oportunidade de crescimento e segurança, relevância social, entre outras dimensões). Notou-se nas pesquisas a associação da temática QVT situações conflituosas no ambiente do trabalho, questões relacionadas à satisfação, envolvimento, comprometimento, identidade organizacional, absenteísmo e, sua carência como preditora de doenças ocupacionais (estresse, fenômeno karoshi, também traduzido literalmente como "morte por excesso de trabalho", lesões por esforços repetitivos - LER, desordens osteomusculares relacionadas a trabalho - DORT e síndromes, como a de burnout).

A partir da contextualização ora traçada, fazse 0 seguinte questionamento: - Qual a percepção dos servidores públicos pertencentes à Divisão de Veículos e Oficina de uma autarquia em Pelotas/RS no que tange ao bem estar no trabalho? Desse modo, o presente trabalho objetiva investigar a percepção de bem-estar dos servidores públicos de uma autarquia gaúcha.
No que tange a parte estrutural do trabalho, este é dividido em três capítulos além do atual. A próxima seção versa sobre os procedimentos metodológicos utilizados para o desenvolvimento da pesquisa. A seção subsequente apresenta a percepção dos servidores públicos pertencentes à DVO de uma autarquia do município de Pelotas, Estado do Rio Grande do Sul, no que tange ao bem-estar no trabalho. 0 quarto capítulo destina-se às considerações finais.

\section{METODOLOGIA}

Por característica, esta pesquisa assumiu tipo descritivo e exploratório, pois foi aprofundado o estudo em busca de informações e dados necessários sobre bem-estar no trabalho, pelo seu caráter subjetivo de investigação, sob a óptica dos colaboradores.

A pesquisa descritiva visa desvendar e observar fenômenos, procurando descrevê-los, classificá-los e interpretá-los, passos esses utilizados para conhecer a sua natureza, composição e processos (GUIMARÃES, 2009), enquanto que a exploratória é realizada, por sua vez, quando há poucos estudos anteriores em que se possam coletar informações sobre um problema ou questão de pesquisa (YIN, 2010).

Quanto ao método utilizado empregou-se 0 estudo de caso no Serviço Autônomo de Saneamento de Pelotas - Sanep, localizado na cidade de Pelotas/RS. Para Yin (2010, p. 65), esse método consiste em "uma investigação empírica, que investiga um fenômeno contemporâneo, em profundidade e em seu contexto de vida real, especialmente quando os limites entre 0 fenômeno e o contexto não são claramente evidentes".

No que tange à abordagem da pesquisa, esta se caracterizou como quantitativa, com vistas a melhor atender o objetivo do trabalho. Para tanto, foi aplicado questionário com os servidores que trabalham na DV0 da referida autarquia e que ocupam o cargo de motoristas, mecânicos, operadores de máquinas, lavador e operário, a fim de verificar suas percepções em relação ao bem-estar no trabalho e fatores condicionantes ao absenteísmo. Cresswell (2007) 
esclarece que a pesquisa quantitativa é realizada para 0 desenvolvimento do conhecimento por meio do raciocínio de causa e efeito, redução de variáveis específicas, hipóteses e questões, mensuração de variáveis, observação e teste de teorias. Nesta pesquisa, após coletados, os dados quantitativos sofreram tratamento estatístico descritivo e análise das correlações.

Ainda em relação ao instrumento de coleta de dados questionário, este foi aplicado presencialmente durante os meses de junho e julho de 2017, com 40 servidores do setor de "Divisão", o que representa uma amostra de $69,0 \%$ de um total de 58 colaboradores do departamento.

Dessa forma, o cálculo da amostra mínima foi respeitado. Para suportar 0 estudo, em nível de confiança de $95 \%$ e erro amostral de $10 \%$ era necessário um número equivalente a 37 sujeitos

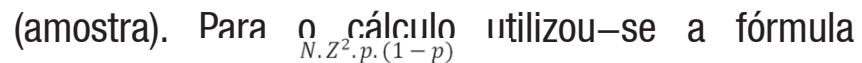

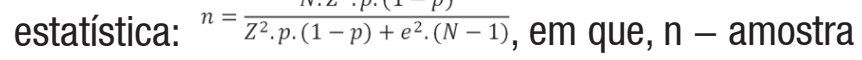
calculada; N - população; Z - variável normal padronizada associada em nível de confiança; $p$ verdadeira probabilidade do evento; e - erro amostral.

0 questionário foi adaptado dos estudos de Siqueira, Orengo e Peiró (2014), Inventário de BemEstar no Trabalho (IBET) composta por 13 questões fechadas, tipo likert de cinco pontos, cujas respostas estão pautadas 1 discordo totalmente, 2 discordo parcialmente, 3 não concordo nem discordo/ não se aplica, 4 concordo parcialmente e 5 concordo totalmente. As denominações, definições, itens e índices de precisão dos fatores da IBET estão assim apresentadas:

1. denominação: compromisso e satisfação.

2. definição: 0 fator contém vínculos positivos para com a organização (compromisso afetivo) e também satisfação com a chefia, salário, promoção e carreira.

3. número de itens: 9

4. índice de precisão: 0,92;

5. denominação: envolvimento com 0 trabaIho.
6. definição: 0 fator é composto por crenças de que 0 trabalho realizado proporciona horas agradáveis e de que nele estão contidos aspectos importantes para a vida.

7. número de itens: 4

8. índice de precisão: 0,87.

Ambos os dados e indicadores passaram por tratamento estatístico descritivo, sendo levantados a média, desvio-padrão, além da realização de teste de confiabilidade por meio da análise do Alpha de Cronbach, cujo valor assumido varia entre 0 e 1, e quanto mais próximo de 1 estiver seu valor, maior a fidedignidade das dimensões do construto. Guimarães (2009) considera para análise a seguinte categoria:
a) intervalos entre 0,0 - 0,2 são classificados como muito baixo;
b) intervalos entre 0,2 - 0,4 são classificados como baixo;
c) intervalos entre 0,4 - 0,6 são classificados como moderado;
d) intervalos entre 0,6 - 0,8 são classificados como bom;
e) intervalos entre $0,8-1,0$ são classificados como alto.

Além disso, recorreu-se à técnica estatística de correlação (matriz de correlação de Pearson) entre os indicadores IBET. De acordo com Hair et al. (2006), maior parte dos coeficientes de correlação deve apresentar valores acima de 0,30.

\subsection{CARACTERIZAÇÃO DA ENTIDADE}

0 Sanep teve origem em 14 de setembro de 1861, quando Ângelo Cassapi propôs um contrato para fornecimento de água de um poço artesiano, que seria levada às casas por encanamento de ferro, esse serviço foi aperfeiçoado por meio dos anos, e em 25 de outubro de 1965 foi criado pela lei no 1.4740 SAAE (Serviço Autônomo de Água e Esgotos), como entidade autárquica municipal, dispondo de autonomia 
econômico-financeira e administrativa. CompetiaIhe com exclusividade operar, manter, conservar e explorar diretamente os serviços de água potável, de esgotos sanitários e os de fossa sépticas e móveis; estudar, projetar e executar as obras relativas aos sistemas públicos de abastecimento de água potável e de esgotos sanitários; lançar, fiscalizar e arrecadar as tarifas dos serviços de água e esgotos; defender os cursos de água do município contra a poluição; e exercer quaisquer outras atividades relativas à água $e$ esgotos. (SANEP, s/d)

A autarquia conta hoje com um total de 872 funcionários que atuam em diversos departamentos, divisões e setores da autarquia, a contratação destes é feita por meio de concurso público, podendo ocorrer contratações emergenciais, quando necessário. (SANEP, s/d)

A forma como o Sanep se relaciona com a prefeitura municipal de Pelotas dá se como uma prestadora de serviços independente, pois o mesmo tem autonomia e receita própria.

\section{RESULTADOS}

Esta subseção procura evidenciar a percepção dos servidores pertencentes ao DVO no que tange ao bem-estar no trabalho.

\subsection{CARACTERIZAÇÃO DOS QUESTIONADOS}

Participaram da pesquisa 40 servidores do departamento de divisão da entidade pública, 0 que representa $69,0 \%$ do total dos servidores do departamento (59), sendo que 95,0\% (38) são do sexo masculino e 80,0\% (32) ocupam 0 cargo de motorista. 0 restante $(20,0 \%, 8)$ ocupa 0 cargo de operador de máquina, mecânico, lavador e operário.

Percebeu que cerca de $85,0 \%$ (34) dos questionados possui faixa etária entre 36 e 55 anos. Outros 5,0\% (2) possuem idade entre 31 e 35 anos, 0 mesmo percentual para idade entre 56 e 60 e superior a 60 anos.
No que se refere à renda, esta se manteve distribuída heterogeneamente entre os questionados, sendo assim, 22,5\% (9) afirmaram possuir renda bruta mensal de até dois salários mínimos ${ }^{5}, 25,0 \%$ (10) alegaram possuir entre dois e três salários mínimos, $22,4 \%$ (9) entre três e quatro salários mínimos e 25,0\% (10) afirmaram possuir mais de cinco salários mínimos; 0 restante, $5,0 \%$ (2), ocuparam faixa correspondente entre quatro e cinco salários mínimos. Além disso, $32,5 \%$ (13) dos questionados afirmaram morar com mais duas pessoas; percentual acompanhado de $22,5 \%$ (9) que declararam que na composição familiar mora com mais três pessoas.

Quando indagados acerca de possuir outra ocupação para complementar a renda, 65,0\% (26) informaram negativamente. Já da parcela que declararam "sim", 27,5\% (11) afirmaram atuar na informalidade, enquanto que $7,5 \%$ (3) complementam sua renda com o trabalho formal.

Tabela 1. Tempo de trabalho na entidade

\begin{tabular}{c|c|c}
\hline Alternativas & $\begin{array}{c}\text { Frequência } \\
\text { absoluta }\end{array}$ & $\begin{array}{c}\text { Frequência } \\
\text { relativa }\end{array}$ \\
\hline Menos de 1 ano. & 0 & $0,0 \%$ \\
\hline De 1 a 5 anos. & 8 & $20,0 \%$ \\
\hline De 6 a 10 anos. & 12 & $30,0 \%$ \\
\hline De 11 a 15 anos. & 12 & $30,0 \%$ \\
\hline De 16 a 20 anos. & 5 & $12,5 \%$ \\
\hline De 21 a 25 anos. & 0 & $0,0 \%$ \\
\hline Mais de 25 anos. & 3 & $7,5 \%$ \\
\hline Total & 40 & $100,0 \%$ \\
\hline
\end{tabular}

Fonte: Dados da pesquisa (2018).

Conforme demonstrado na Tabela 1, 60,0\% (24) concentram-se entre seis a 15 anos de empresa, o que é comum por se tratar de entidade pública.

Em decorrência do grau exigido de formalização e critério de seleção exercido pela autarquia para com 5 Referência do salário mínimo R\$937,00, segundo portaria MF № 8, de 13 de janeiro de 2017, disponível em: <http://normas.receita.fazenda. gov.br/sijut2consulta/link.action?visa0=anotado\&idAto=79662> . 
seus servidores públicos, a metade dos questionados $(50,0 \%)$ possui como titulação máxima o ensino médio completo (regular e/ou técnico). Dos questionados, $7,5 \%$ (3) possuem ensino superior completo, enquanto que $10,0 \%$ (4) estão em curso e o restante, $15,0 \%$ (6) distribuídos em ensino fundamental completo $(7,5 \%) \mathrm{e}$ fundamental incompleto $(7,5 \%)$.
A Figura 1 apresenta a média e 0 respectivo desvio-padrão obtido por cada fator, quais sejam: (a) compromisso e satisfação e (b) envolvimento com 0 trabalho.

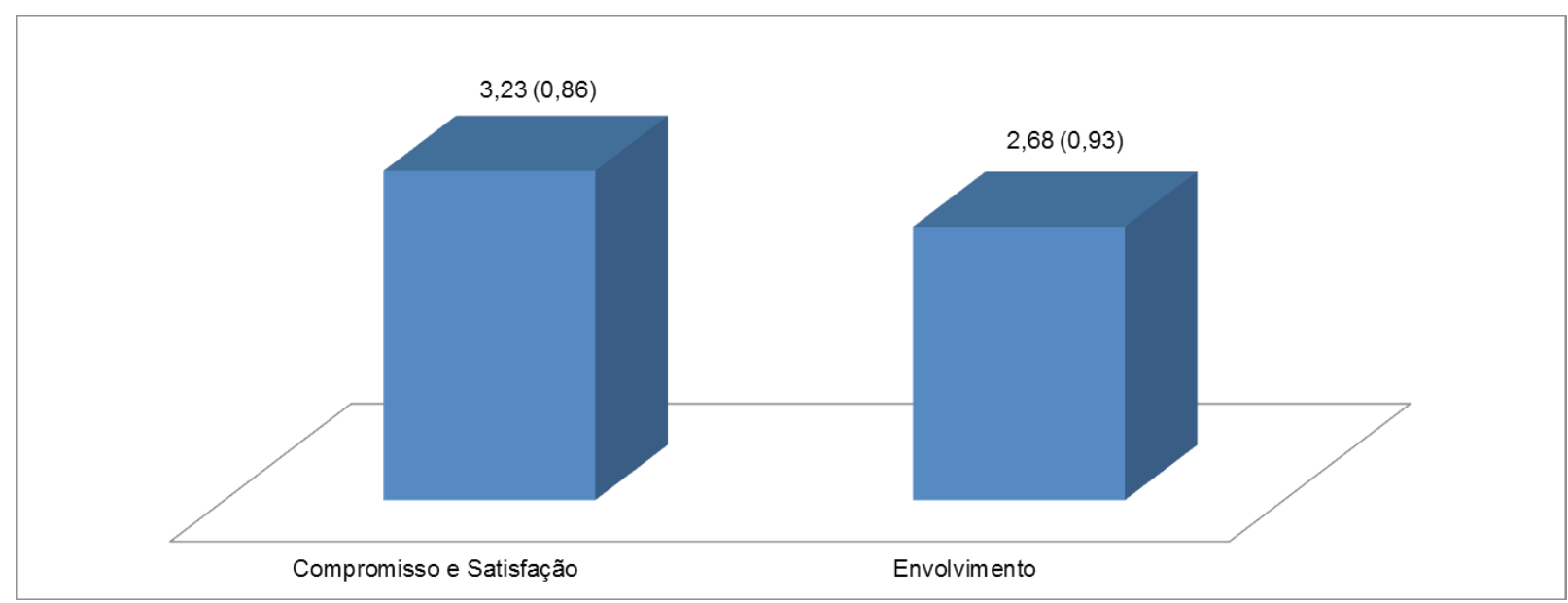

Figura 1. Percepção dos fatores de bem-estar e satisfação e envolvimento com o trabalho Fonte: dados da pesquisa (2018)

A Tabela 2 apresenta 0 teste da correlação de Pearson entre as variáveis que compõem 0 constructo de bem-estar no trabalho do IBET.

Tabela 2. Correlação das variáveis do Inventário de Bem-Estar no Trabalho

\begin{tabular}{|c|c|c|c|c|c|c|c|c|c|c|c|c|c|}
\hline & var1 & var2 & var3 & var4 & var5 & var6 & var7 & var8 & var9 & var10 & var11 & var12 & var13 \\
\hline var1 & 1 & & & & & & & & & & & & \\
\hline var2 & 0,689 & 1 & & & & & & & & & & & \\
\hline var3 & 0,515 & 0,520 & 1 & & & & & & & & & & \\
\hline var4 & 0,262 & 0,489 & 0,190 & 1 & & & & & & & & & \\
\hline var5 & 0,282 & 0,231 & 0,211 & 0,112 & 1 & & & & & & & & \\
\hline var6 & 0,592 & 0,717 & 0,521 & 0,527 & 0,387 & 1 & & & & & & & \\
\hline var7 & 0,302 & 0,317 & 0,340 & 0,064 & 0,105 & 0,240 & 1 & & & & & & \\
\hline var8 & 0,216 & 0,333 & 0,416 & 0,349 & 0,126 & 0,464 & 0,286 & 1 & & & & & \\
\hline var9 & 0,245 & 0,197 & 0,474 & $-0,075$ & $-0,119$ & 0,011 & 0,325 & 0,276 & 1 & & & & \\
\hline var10 & 0,288 & 0,171 & 0,302 & $-0,003$ & 0,044 & 0,095 & $-0,363$ & 0,058 & 0,126 & 1 & & & \\
\hline var11 & 0,446 & 0,538 & 0,259 & 0,288 & 0,492 & 0,593 & 0,244 & 0,009 & $-0,084$ & 0,086 & 1 & & \\
\hline var12 & 0,138 & 0,296 & 0,409 & 0,150 & 0,226 & 0,155 & 0,185 & 0,119 & 0,119 & 0,266 & 0,246 & 1 & \\
\hline var13 & 0,296 & 0,434 & 0,426 & 0,345 & 0,263 & 0,509 & 0,285 & 0,304 & 0,108 & 0,102 & 0,335 & 0,299 & 1 \\
\hline
\end{tabular}

Fonte: Dados da pesquisa (2018). 
Var 1 - Estou contente com a empresa onde trabalho. Var 2 - Estou entusiasmado com a empresa onde trabalho.

Var 3 - As horas que passo trabalhando são as melhores horas do meu dia.

Var 4 - Estou interessado na empresa onde trabalho. Var 5 - Estou satisfeito com meu salário comparado com meus esforços no trabalho.

Var 6 - Estou animado com a empresa onde trabalho. Var 7 - As maiores satisfações de minha vida vêm do meu trabalho.

Var 8 - Estou satisfeito com o grau de interesse que minhas tarefas despertam em mim.

Var 9 - As coisas mais importantes que acontecem em minha vida envolvem meu trabalho.

Var 10 - Estou satisfeito com 0 entendimento entre mim e meu chefe.

Var 11 - Estou orgulhoso da empresa onde trabalho. Var 12 - Eu como, vivo e respiro meu trabalho.

Var 13 - Estou satisfeito com as oportunidades de ser promovido nesta empresa.

Nota 1 - Pertencem ao construto compromisso e satisfação as variáveis var1, var2, var4, var5, var6, var8, var10, var11 e var13.

Nota 2 - Pertencem ao construto envolvimento as variáveis var3, var7, var9 e var12.

\section{DISCUSSÃO}

0 construto compromisso e satisfação no trabalho apresentou alpha de cronbach com um índice de confiabilidade em torno de $81 \%$. Sob esse foco, é possível verificar que os indicadores que compõem este grupo/bloco apresentam "alta" relação com o compromisso e satisfação, de acordo com a classificação de Guimarães (2009).

$\mathrm{Na}$ Figura 1 observa-se que 0 aspecto compromisso e satisfação no trabalho ancoraram com média $x=3,23$ ( $D P=0,86$ ), alocando em região por demais próxima ao ponto neutro. 0 que leva a interpretar que as possibilidades de 0 trabalhador vivenciar períodos em que emergem dentro dele, de forma interligada, sentimentos positivos promovidos por aspectos presentes no ambiente laboral estão sendo por eles questionadas, no que tange à satisfação no trabalha e comprometimento organizacional afetivo que, segundo Siqueira, Orengo e Peiró (2014), arrola sobre os sentimentos positivos dirigidos à organização que a emprega (estar contente, entusiasmado, interessado, animado e orgulhoso com o trabalho).

$\mathrm{Na}$ análise por fatores, percebeu-se maior média do construto compromisso e satisfação a variável $10(x=4,40$; $D P=1,18)$ que se referia a estar satisfeito com 0 entendimento entre mim e meu chefe, o que leva a crer a bom relacionamento com o chefe imediato. A segunda maior média apontou a variável 8 $(x=3,90 ; \mathrm{DP}=1,32)$ e diz respeito a estar satisfeito com 0 grau de interesse que as tarefas despertam no trabalhador.

Em contrapartida, as menores médias se concentraram nas variáveis $13(x=1,73 ; \mathrm{DP}=$ $1,12)$ que diz respeito a estar satisfeito com as oportunidades de ser promovido nesta empresa e, variável $5 b(x=2,55$; $D P=1,53)$ que exprime satisfação com salário comparado com os esforços no trabalho. Infere-se análise sobre a variável 13 , podendo justificar das limitações da entidade pública no que tange à flexibilização na ascensão de servidores em cargos e funções. No entanto, a literatura voltada para gestão de pessoas apresenta para organizações públicas formas inteligentes e motivacionais de gerir os recursos humanos e remunerar de acordo com suas contribuições e resultados, uma dessas formas é a gestão por competências (DUTRA, 2011).

No que se refere ao conjunto de indicadores que compõe o construto envolvimento no trabalho apresentou por meio do alpha de cronbach, índice de confiabilidade em torno de $63 \%$, considerada "boa" (GUIMARÃES, 2009).

Nota-se um ponto crítico no que se refere ao aspecto envolvimento; sua média esteve abaixo do ponto neutro ( $x=2,68, \mathrm{DP}=0,93$ ), como demonstrou a Figura 1, 0 que significa que os colaboradores não se sentem envolvidos com a organização nem a enxergam com esmero, ou seja, não demonstra 
sensações de harmonia entre suas habilidades profissionais e exigências impostas pelas atividades que realiza (SIQUEIRA; ORENGO; PEIRÓ, 2014).

$A$ variável 12 apresentou menor expressão $(x=$ $2,38, D P=1,35)$ e referia à aspiração: "eu como, vivo $e$ respiro meu trabalho". Por conseguinte, 0 indicador $9 \mathrm{~b}$ (as coisas mais importantes que acontecem em minha vida envolvem meu trabalho) apresentou a segunda menor média $(x=2,65, D P=1,28)$. Esta variável foi acompanhada da $3(x=2,78, D P=1,23)$ que se refere à declaração "- as horas que passo trabalhando são as melhores horas do meu dia". Por fim, o último indicador do construto, a variável $7 \mathrm{~b}$ que diz respeito a "as maiores satisfações de minha vida vêm do meu trabalho" obteve média que mais se aproximou ao ponto neutro $(x=2,93, \mathrm{DP}=1,51)$.

Diante dos dados acerca do IBET sendo pouco percebido pelos colaboradores demonstra pouca preocupação da entidade com a saúde, a segurança e o bem-estar de seus funcionários. De acordo com Bezerra (2016), este aspecto assume relevância por promover um ambiente de trabalho adequado, capaz de garantir a saúde ocupacional, a segurança no trabalho e, assim, o bem-estar físico, psíquico e mental dos colaboradores.

$\mathrm{Na}$ análise das correlações, conforme demonstrada na Tabela 2, apresentou maior correlação, isto é, o entendimento de como uma variável se comporta em um cenário onde outra está variando, visando identificar se existe alguma relação entre a variabilidade de ambas, notou-se que é forte a associação entre as variáveis var2, "Estou entusiasmado com a empresa onde trabalho" com var6 "Estou animado com a empresa onde trabalho", na proporção de $71,7 \%$, acompanhada com a associação entre as variáveis var1 "Estou contente com a empresa onde trabalho" em relação à var2, com percentual de 68,9\%. Apesar de apresentarem forte correlação, em que julgam os servidores serem variáveis e aspectos importantes para promoção de bem-estar, chama a atenção 0 fato de as médias serem relativamente baixas $(\operatorname{var} 1=\times 3,65$; var2 $=$ $\times 3,05$; var6 $=x 2,78$ ), encontrando-se próximas ao ponto neutro (não concordo nem discordo). Diante desses dados, recomenda-se a entidade desenvolver estratégias voltadas a investigar as razões pelas quais os colaboradores não se sentem plenamente contentes, entusiasmados e animados com o trabalho.

\section{CONCLUSÃO}

0 presente trabalho objetivou investigar a percepção dos servidores públicos pertencentes à Divisão de Veículos e Oficina (DVO) de uma autarquia do município de Pelotas/RS em relação ao bem-estar no trabalho.

Pode-se concluir que dentro do construto de bem-estar no trabalho, 0 aspecto envolvimento obteve menor média (x 2,68, DP 0,93). Diante dos resultados apresentados, recomenda-se que a entidade desenvolver ações que venham proporcionar bem-estar aos seus servidores, sobretudo no que tange ao "Envolvimento", especificamente aos itens relacionados que venham proporcionar reconhecimento e valor do trabalho na autarquia de modo a reconhecerem que "Eu como, vivo e respiro meu trabalho" (var. 12), "As coisas mais importantes que acontecem em minha vida envolvem meu trabalho" (var. 9) e "As horas que passo trabalhando são as melhores horas do meu dia" (var. 3). Ambas variáveis receberam as menores avaliações pelos servidores.

Apesar de atingir o objetivo proposto pelo estudo, reconhecem-se limitações da pesquisa. A primeira recai sobre 0 método utilizado, 0 estudo de caso, ou seja, os resultados não podem ser extrapolados e generalizados. A segunda limitação recai sobre a amostra e delimitação da pesquisa ser estendida apenas aos servidores pertencentes ao setor DV0.

Dessa forma, sugerem-se como estudo futuros, pesquisas relacionadas sobre a temática QVT abrangendo os aspectos satisfação, comprometimento e envolvimento em amostras substancialmente maiores na própria entidade pública Sanep e demais 
entidades da região sul-rio-grandense, com intuito de conhecer a realidade e percepção dos servidores e propor melhorias, planos de ação e programas de melhoramento de índices de QVT e bem-estar laboral, vez que conforme Vieira (2014) e Rocha, Passado e Shinyashiki (2017), as pessoas são molas propulsoras para 0 desenvolvimento organizacional, à medida que por meio delas emanam a capacidade criativa, inovadora e reflexiva; capacidades essas tão demandadas nos dias atuais.

\section{REFERÊNCIAS}

ALBUQUERQUE, L.G.; LIMONGI-FRANÇA, A.C. Estratégias de recursos humanos e Gestão da Qualidade de Vida no Trabalho: 0 stress e a expansão do conceito de qualidade total. Revista de Administração, v. 33, n. 2, p. 40-51, 1998.

\section{BEZERRA, M.E.A. 0 papel das Políticas e Práticas de} Gestão de Pessoas na construção da Identidade Organizacional. 2016. 94f. Monografia (graduação) - Universidade de Brasília. Faculdade de Economia, Administração e Contabilidade. Brasília, DF, 2016.

BATTISTON, M.; CRUZ, R.M.; HOFFMANN, M.H. Condições de trabalho e saúde de motoristas de transporte coletivo urbano. Estudos de Psicologia (Natal), v. 11, p. 333-343, 2006.

CARVALHO-FREITAS, M.N. Inserção e gestão do trabalho de pessoas com deficiência: um estudo de caso. Revista de Administração Contemporânea, v. 13, n. n. spe, p. 121-138, 2009.

CAVEDON, N. R. A qualidade de vida no trabalho na área da Segurança Pública: uma perspectiva diacrônica das percepções olfativas e suas implicações na saúde dos servidores. Organizações \& Sociedade, v. 21, n. 68, p. 875-892, 2014.

CRESSWELL, J.W. Projeto de Pesquisa: Métodos Qualitativo, Qualitativo e misto. 2 ed. Porto Alegre; ARTMED, 2007.
DAVID, L.M.L.; FARIA, M.F.B. Qualidade de vida no trabalho: construção e validação de uma escala em organizações militares do Exército. Revista de Administração, v. 42, n. 4, p. 431-442, 2007.

DOURADO, D.C.P.; CARVALHO, C.A. Extra! Extra! 0 caso do Metrorec revela como é operada a manipulação ideológica do discurso da QVT. Cadernos EBAPE.BR, v. 5, n. 4, p. 1-16, 2007.

DOURAD0, D.C.P.; CARVALHO, C.A. Controle do homem no trabalho ou qualidade de vida no trabalho?. Cadernos EBAPE.BR, v. 4, n. 4, p. 1-15, 2006.

DUTRA, J.S. Gestão de pessoas: modelo, processos, tendências e perspectivas. São Paulo: Atlas, 2011.

EL-AOUAR, W.A.; VASCONCELOS, C.R.M.; VEIGA NETO, A.R. Quality of Working Life and Music in the Manufacturing Workplace. Organizações \& Sociedade, v. 23, n. 79, p. 656-674, 2016.

FERNANDES, E.C.; GUTIERREZ, L.H. Qualidade de Vida no Trabalho (QVT) uma experiência brasileira. Revista de Administração, v. 23, n. 4, p. 29-38, 1988.

FERNANDES, E.C.; RENDÓN, J.V. Sondagens de opinião interna como instrumento de informação. Revista de Administração, v. 27, n. 1, p. 36-48, 1992.

GOUVEIA, A.M. et al. Análise da qualidade de vida no trabalho em caminhoneiros de uma indústria petrolífera. RESC: Revista Eletrônica Saúde e Ciência, v. 2, n. 02, 2012.

GUIDELLI, N.S.; BRESCIANI, L.P. Inovação e qualidade de vida no trabalho: uma visão integrada da gestão a partir de estudo de caso na indústria petroquímica do Grande ABC. Revista de Administração, v. 45, n. 1, art. 5, p. 57-69, 2010.

GUIMARÃES, J.B.S. Análise Estatística Utilizando o SPSS Guia prático de comandos.2009. Disponível em: <http://www.prograd.uff.br/estatistica/sites/ default/files/Apostila-SPSS.pdf>. Acesso em 07 jan. 2017. 
HAIR, Jr; BLACK, W.C.; BABIN, B.J.; ANDERSON, R.E; TATHAM, R.L. Multivariate Data Analysis. 6. ed. UpperSaddle River, NJ: Pearson Prentice Hall, 2006.

HONÓRIO, L.C.; MARQUES, A.L. Reforma estrutural das telecomunicações no Brasil: um estudo sobre a qualidade de vida no trabalho em uma empresa de telefonia celular. Revista de Administração, v. 36, n. 2, p. 57-66, 2001.

MONACO, F.F.; GUIMARÃES, V.N. Gestão da qualidade total e qualidade de vida no trabalho: 0 caso da Gerência de Administração dos Correios. Revista de Administração Contemporânea, v. 4, n. 3, p. 67-88, 2000.

OLIVEIRA, L.B.; CAVAZOTTE, F.S.C.N.; PACIELLO, R.R. Antecedentes e consequências dos conflitos entre trabalho e família. Revista de Administração Contemporânea, v. 17, n. 4, p. 418-437, 2013.

PAIVA, K.C.M.; AVELAR, V.L.L.M. Qualidade de vida no trabalho em uma central de regulação médica de um serviço de atendimento móvel de urgência (SAMU). Organizações \& Sociedade, v. 18 , n. 57 , art. 6, p. 303-321, 2011.

PAIVA, K.C.M.; COUTO, J.H. Qualidade de vida e estresse gerencial "pós-choque de gestão": o caso da Copasa-MG. Revista de Administração Pública, v. 42, n. 6, p. 1189-1211, 2008.

SILVA, J.M.; MATOS, F.R.N. Qualidade de Vida no Trabalho e produtividade na indústria da castanha. 2003.

PENTEADO, R.Z. et al. Trabalho e saúde em motoristas de caminhão no interior de São Paulo. Saúde e Sociedade, v. 17, n. 4, p. 35-45, 2008.

ROCHA, G.B.; PASSADOR, C.S.; SHINYASHIKI, G.T. What is the Social Gain from Competency Management? The Employees' Perception at a Brazilian Public University. Revista de Administração, v. 52, n. 3, p. 233-245, 2017.
RUEDA, F.J.M.; SERENINI, A.L.P.; MEIRELES, E. Relação entre qualidade de vida no trabalho e confiança do empregado na organização. Revista Psicologia Organizações e Trabalho, v. 14, p. 303-314, 2014.

SANEP - Serviço Autônomo de Saneamento de Pelotas. Histórico. Disponível em: <http://www.pelotas.rs.gov. br/sanep/sobre-0-sanep/>. Acesso em: 27 jul. 2017.

SIQUEIRA, M.M.M.; ORENGO, V.; PEIRÓ, J.P. Bem-estar no trabalho. In: SIQUEIRA, M. M. M, Novas Medidas do Comportamento Organizacional: Ferramentas de Diagnóstico e de Gestão. - Porto Alegre: Artmed, 2014.

TOLF0, S.R.; PICCININI, V.C. As melhores empresas para trabalhar no Brasil e a qualidade de vida no trabalho: disjunções entre a teoria e a prática. Revista de Administração Contemporânea, v. 5, n. 1, p. 165-193, 2001.

VIEIRA, S.M. Gestão Estratégica de Pessoas na Administração Pública: Um Estudo de Caso na Secretaria Municipal de Saúde de Brumado/BA. NAU Social, v. 5, n. 9, 2014.

YIN, R.K. Estudo de Caso: planejamento e métodos. 4. ed. Porto Alegre: Bookman, 2010.

Recebido em: 03/05/2018 Aceito em: 29/05/2018 